\title{
Tratar as COISAS COMO FATOS SOCIAIS: METAMORFOSES NOS ESTUDOS SOBRE CULTURA MATERIAL $^{1}$
}

\author{
Débora Krischke Leitão ${ }^{2}$ \\ Rosana Pinheiro-Machado ${ }^{3}$
}

\begin{abstract}
Resumo
Procuramos analisar como a cultura material foi abordada na Antropologia, ao longo de alguns momentos de sua história. Discutimos igualmente propostas contemporâneas, surgidas, em sua maioria, nos estudos sobre consumo. Por último, sugerimos suas possíveis contribuições, discutindo em que medida a transformação na abordagem antropológica da cultura material traz inovações e provocações para que repensemos nossas práticas.
\end{abstract}

Palavras-chave: Cultura Material. Antropologia. Objetos. Mercadoria.

\footnotetext{
${ }^{1}$ Uma versão inicial desse artigo foi apresentada, em 2008, no 320 Encontro Anual da ANPOCS.

${ }^{2}$ Professora adjunta do departamento de Antropologia. Universidade Federal de Mato Grosso. Doutora em Antropologia Social (PPGAS/UFRGS). End. Eletrônico: dekl@terra.com.br

${ }^{3}$ Professora da Escola Superior de Propaganda e Marketing (ESPM/RS). Doutora em Antropologia Social pela UFRGS. End. Eletrônico: rmachado@espm.br
} 


\title{
Treating things as Social Facts: Metamorphoses in the Studies About Material Culture
}

\begin{abstract}
In this article, we intend to analyze how material culture has been approached in Anthropology in some moments in its history. We discuss contemporary proposals, most of which came up from studies about consumption. Finally, we suggest their potential contributions and discuss how the transformation in the anthropological approach of material culture brings innovation and incites us to rethink our practices.
\end{abstract}

Keywords: Material Culture. Anthropology. Objects. Commodity.

"Provavelmente aquelas coisas tinham nomes. 0 menino mais novo interrogou-o com os olhos. Sim, com certeza as preciosidades que se exibiam nos altares da igreja e nas prateleiras das lojas tinham nomes [...]. Vistas de longe, eram bonitas. Admirados e medrosos, falavam baixo para não desencadear as forças estranhas que elas por ventura encerrassem" (Graciliano Ramos, Vidas Secas).

$\mathrm{P}$ reciosos, desejados, excepcionais ou ordinários e imperceptíveis, os objetos nos rodeiam. É em interação com eles, no cotidiano, que construímos nossa existência no mundo. Por essa razão, a relação entre sujeitos e objetos tem sido, de maneira renovada, tema caro às Ciências Sociais. Mas, a partir de quais perspectivas podemos nos debruçar sobre essa relação? Qual o lugar ocupado pelas coisas em nossas pesquisas empíricas e propostas teóricas? Essas e outras questões motivam a reflexão aqui esboçada. Analisamos, em primeiro lugar, modelos de compreensão do mundo material que estiveram presentes na antropologia, pensando sobre sua relação com os paradigmas teóricos aos quais correspondem. Em seguida, buscamos contextualizar as propostas contemporâneas, discutindo possíveis inovações que são trazidas quando, a exemplo do que sugere Bruno Latour (2007), em uma inversão irônica da máxima durkheimiana, passamos a tratar as coisas como fatos sociais. Tal perspectiva de uma "revitalizada antropologia das coisas" pode trazer contribuições para diversas áreas de pesquisa, desde os estudos das ciências sociais sobre o consumo de objetos, até suas reflexões sobre identidades, memória, artes, museus e políticas de patrimônio. 
Este artigo está divido em três partes. Na primeira, veremos a lugar dos objetos enquanto categoria analítica nas ciências sociais. Na segunda, o "espírito" das mercadorias será discutido, no intuito de atualizar o questionamento acerca do dualismo criado na Antropologia entre mercadoria e dádiva. Para finalizar, apresentaremos algumas pesquisas que versam sobre a possibilidade de uma conciliação entre os estudos de cultura material e as premissas clássicas sobre identidade social e étnica.

\section{ÁLBUM DE FAMÍLIA: POSSÍVEIS TRAJETÓRIAS DAS "COISAS" NAS CIÊNCIAS SOCIAIS}

Com o objetivo de identificar as abordagens das Ciências Humanas para com a cultura material, Turgeon (2007) elabora uma classificação que contempla quatro momentos ou "fases" pelas quais teriam passado os objetos. Tais fases, correspondentes a diferentes momentos históricos e correntes teóricas, seriam 0 que chama de "objeto testemunha", "objeto signo", "objeto social" e "objeto memória".

Fabian (2004), por sua vez, é mais econômico em sua classificação, identificando apenas o que chama de "material culture old style" e "material culture new style". Já que privilegia a polarização entre "antigo" e "novo", o contraste, em Fabian, mostra-se mais acentuado. Naquilo que o autor define como "old style" poderíamos situar tanto a categoria do "objeto testemunha" quanto a categoria do "objeto signo", ao passo que o que Fabian define como "new style" englobaria tanto o "objeto social" quanto o "objeto memória" de Turgeon.

Unindo as duas propostas, preferimos pensar em três categorias de abordagens para com a cultura material. Concordamos com a distinção feita por Turgeon (2007) entre o objeto testemunha e o objeto signo, já que falam de olhares díspares com relação aos objetos. Não compartilhamos, entretanto, da separação feita entre o objeto social e o objeto memória, preferindo agrupá-los em uma categoria única que poderíamos chamar de "objeto construtor".

A primeira dessas fases, a do "objeto testemunha", coincide com o surgimento da Antropologia enquanto ciência. Ela situa os objetos na posição de dado ou documento capaz de fornecer pistas à compreensão das culturas afastadas no tempo e/ou no espaço da cultura ocidental. Como diz Turgeon (2007), ela corresponde claramente à divisão eurocêntrica entre um nós "civilizado", cuja 
historicidade pode ser verificada através de documentos escritos e um Outro "não-civilizado", "sem escrita" e "sem história". Os objetos, dado bruto que se pode obter do Outro em questão, servem para documentar de maneira objetiva e concreta tradições e costumes.

A fase do "objeto testemunha" coincide com aquela dos grandes museus etnográficos, verdadeiras "máquinas de fabricar autenticidades" (CLIFFORD, 1985). Eles testemunhavam tanto alteridade (ABREU, 2005), materializando a diferença do Outro exótico, quanto autoridade, na medida em que serviam de evidência capaz de comprovar a veracidade das teorias antropológicas.

0 Evolucionismo Cultural é, com frequiência, acusado por sua posição etnocêntrica, situando, através da comparação de traços culturais, as sociedades em fases de desenvolvimento que teriam como ápice a "civilização", exemplificada na "boa" sociedade ocidental do século XIX. Os próprios critérios de comparação, a exemplo daqueles tomados como centrais por Morgan (1974), privilegiam a técnica e o avanço tecnológico das sociedades, correspondendo ao imaginário do "progresso" técnico tão caro ao mundo ocidental do século XIX.

Os objetos coletados, inventariados e comparados testemunharam, aos olhos da época, as próprias leis da evolução. Curiosamente, também foram eles as testemunhas silenciosas de outras leis, as da difusão cultural, mostrando-nos, em certa medida, que o que os objetos concerniam menos a eles e mais ao uso que deles era feito após serem retirados de seu contexto cultural.

Naquele momento "old style", segundo Fabian (2004), as coisas são desmaterializadas, já que fora de seu contexto de origem perdem sua especificidade enquanto "objetos" para se tornarem "artefato etnográfico". No entanto, elas são também acompanhantes da coisificação de outros domínios que, em princípio, não teriam nada a ver com as "coisas" materiais, como "mitos, canções, rituais, instituições e crenças" (FABIAN, 2004, p. 52), mas que são tratados enquanto tal.

Embora em Malinowski (1978) os objetos não sirvam para, através da comparação entre culturas, extrair "leis gerais" e princípios comuns, eles continuam, aos olhos de Turgeon (2007), testemunhando: eles testemunham a singularidade e a coerência das culturas que os produzem e que deles fazem uso, e no seio das quais ocupam uma função específica.

Na abordagem que Turgeon (2007) define como "objeto signo", o olhar para com as coisas se transforma. 0 objeto deixa de ser dado bruto ou testemunha 
de algo do passado ou distante, ele "comunica" e "representa". Indo além do uso, tomar o objeto como signo implica em se interessar por seus sentidos. Dotado a partir de então de função enunciativa, ele carrega significados e, a semelhança de um texto, poderá ser lido, analisado, decodificado.

É interessante perceber que justamente nessa passagem, de testemunha a signo, outros objetos mais "próximos" são colocados em questão. 0 foco não está mais unicamente naqueles situados enquanto "traço do passado" ou "traço do Outro", podendo ser igualmente o objeto inscrito na vida contemporânea passível de interpretação e "leitura".

Ainda que Barthes, no Sistema da Moda (2003), trate mais dos discursos sobre as roupas do que propriamente das roupas enquanto discurso, já que centra sua análise no texto das revistas de moda, em Mitologias (2001), temos alguns exemplos de como os objetos serão percebidos enquanto um sistema comunicacional. No entanto, é em Baudrillard $(1996,2002)$ que essa abordagem se potencializa: os objetos são vias de acesso para os sistemas simbólicos de nossa sociedade e o consumo é concebido enquanto "manipulação sistemática de signos".

Tanto em Barthes quanto em Baudrillard os objetos não são mais testemunhas solitárias. Seu significado será transformado quando, associados a outros objetos, puderem compor um discurso coerente. Nessa hipótese, seu sentido não será dado por cada unidade autônoma, mas pelo conjunto e pelo tipo de relação estabelecida entre os termos. Encontramos em Baudrillard (2002) os exemplos sobre os arranjos de interiores domésticos. Já em Barthes (1990), temos a famosa análise do anúncio publicitário das massas Panzani, na qual o significado da "verdadeira comida italiana" somente será obtido a partir do conjunto formado por " [...] pacotes de massas, uma lata, tomates, cebolas, pimentões, um cogumelo, todo o conjunto saindo de uma sacola de compras entreaberta, em tons de amarelo e verde sobre fundo vermelho" (BARTHES, 1990, p. 28).

Uma crítica frequentemente feita a tal abordagem é a de que, concebendo as coisas como "texto", perder-se-ia a própria especificidade dos objetos que, em sua materialidade, são feitos para serem usados, para agir no mundo. Eles são bons para usar e bons para viver, não apenas "bons para pensar". Em parte essa é a crítica que faz Gell (1998) ao que identifica como uma abordagem semiótica das coisas. Keane (2005), entretanto, sugere que Gell tenha cometido um equívoco ao associar uma abordagem semiótica à postura que se restringe à decifração dos 
objetos, tomando-os como um tipo de linguagem igual ao texto, unicamente como uma referência a um sentido "imaterial", separado do mundo material e concreto.

Outra crítica que é feita à abordagem dos objetos enquanto signos é a de que não há verdadeira preocupação em compreender os objetos em si, ou a relação dos sujeitos com os objetos, mas, apenas a tentativa de extrair deles algo mais "verdadeiro" e "importante" do que as coisas em si. Através do objeto, através do que ele "comunica", seria possível chegar a algo "escondido atrás dele", "não manifesto na realidade objetiva". Seria preciso, então, desvendar e decodificar as coisas para, tirando a capa da materialidade e da realidade aparente, encontrar algo como "a sociedade", "as relações sociais" ou "a cultura".

Tal crítica, feita por Miller $(2005,2007)$ entre outros, ajuda-nos a compreender porque os estudos sobre os objetos (ou sobre o consumo) são, por vezes, situados à margem, vistos como menos importantes. A separação entre material e imaterial traz, além da oposição, uma hierarquia. 0 dualismo entre sujeitos e objetos faz com que o mundo material seja visto como dotado de uma natureza ilusória, e os muitos ditados que falam sobre "aparências" até estão para comprovar tal desconfiança.

Essas críticas fundamentam as idéias que deram origem ao que chamamos aqui de "objeto construtor", coincidente com a abordagem que Fabian (2004) rotulou de new style. Tal ponto de vista é caracterizado, sobretudo, pelo interesse em compreender o que os objetos fazem no mundo, sua capacidade de atuação. Para ele, os objetos constroem as pessoas tanto quanto as pessoas fabricam objetos. E muito embora Fabian cite nessa categoria apenas autores como Miller, Appadurai, Gell e Clifford, acreditamos que alguns outros, por vezes situados em uma abordagem mais identificada ao "objeto signo", também poderiam ser lidos como precursores dessa postura que concede às coisas poder de ação no mundo.

É o caso, por exemplo, de Pierre Bourdieu (1970). Embora sua primeira análise da maison kabyle seja, com freqüência, apontada como exemplo das influências estruturalistas que, à época, permeavam seu pensamento, podemos pensar que tanto ali, quanto no uso posterior que faz dela (BOURDIEU, 1999), os objetos também agem sobre o mundo social. A casa kabyle será, a um só tempo, a representação das relações sociais e do sistema de pensamento e a própria responsável pela manutenção e pelo aprendizado de tais relações sociais. A relação entre sujeito e objeto já é ali dialética: os sujeitos constroem, produzem e arranjam os objetos de acordo com um sistema de pensamento que compartilham, mas, 
por outro lado, esses mesmos objetos são fundamentais na construção do próprio sistema.

Uma vez que, seguindo a sugestão de Latour (2007), tratamos as coisas como "fatos sociais", procurando abolir a distinção de substância entre sujeitos e objetos, podemos perceber as relações sociais como não sendo necessariamente anteriores aos objetos a elas associados, mas, a um só tempo, constitutivas e construídas por tais objetos.

Outra conseqüência importante da abordagem "new style" da cultura material é que, uma vez que os significados não são anteriores aos objetos, a ação ou mediação que executam entre os sujeitos e o mundo social é vista como dotada de maior flexibilidade. Consumo e circulação de objetos podem, recontextualizando os bens, reconfigurar e modificar seus sentidos e seus usos. Nesse sentido, podemos conceber as "cercas e pontes" de Douglas e Isherwood (2004) como sendo construídas, cotidianamente e dentro de contextos específicos, e não apenas expressadas, nas relações de consumo.

Retomando a classificação proposta por Turgeon (2007), sugerimos também, mais adiante, que a concepção de que os objetos são capazes não apenas de expressar memória e a identidade, mas de criá-las e transformá-las - o objeto memória - só é possível a partir da noção de que seu significado é flexível e de que ele tem poder de transformar o mundo social. 0 "objeto memória", nesse sentido, não seria uma abordagem diferente daquela do "objeto social", mas uma conseqüência desta.

\section{O Espírito das Mercadorias}

Nos últimos anos, mercadorias passaram a receber um novo tratamento na disciplina e isso se deve a inúmeras razões: 0 uso dos bens passa a ser entendido como uma forma da própria compreensão da desigualdade social e da formação de classes; percebe-se que mercadorias são humanizadas e domesticadas, quebra-se a polaridade entre gift e mercadoria; e, em uma perspectiva mais contemporânea, entende-se que o estudo da sua cadeia total (da produção ao consumo) ajuda a desfetichizar a mercadoria, desvelando as relações humanas presente ao longo do processo.

Assim, a ênfase no estudo de uma commodification social se fortaleceu a partir do final dos anos 70, através de dois pontos de vista inter-relacionados: 
a circulação de mercadorias e o consumo. Miller (1995, p. 142) identifica que o extraordinário silêncio sobre consumo, que aconteceu entre os anos 50 e 70 quando havia somente pesquisas sobre produção de mercadorias e trabalho -, foi quebrado com dois estudos publicados em 1979, um de Mary Douglas e outro de Pierre Bourdieu. Posteriormente, nos anos 80, Arjun Appadurai e o próprio Miller ocuparam um importante lugar nos estudos sobre o tema. Este último, resgatando a filosofia hegeliana usada por Marx e Simmel, contextualizou o consumo nos termos de uma cultura da objetificação, a qual pressupõe que a existência humana dos sujeitos é mediada por objetos. Ele, então, enfatiza o potencial ativo do consumidor como (re) socializador das mercadorias (MILLER, 1995, p. 143), bem como sua agência de transformar mercadorias impessoais em coisas pessoais ou domesticadas. Por outro lado, através de uma visão dialética, a relação inversa é igualmente importante, quando bens atuam sobre os indivíduos através de sua capacidade de expressar o "eu" (self) e, além disso, de expressar e produzir afetos interpessoais.

Para o autor, o indivíduo só concebe a si próprio através de um processo de objetificação. Não existe um indivíduo à priori do "realismo": a consciência é baseada em uma relação entre o ideal e o material, em que cada uma dessas categorias existe em relação à outra (MILLER, 1987). Nós somos humanos através de um mundo material que nos media, nos informa e nos limita, na mesma medida em que esse mundo material é classificado ordenado e interpretado.

Esse ponto de vista, que destaca o papel das mercadorias como agente central na vida dos indivíduos, vai reaparecer em diversos livros do referido autor, produzidos ao longo das últimas duas décadas. Trata-se do estudo do consumo de objetos como celular, Coca-cola, carro, calça jeans ou, até mesmo, sobre 0 conforto das coisas de nossas casas. Na realidade, é possível dizer que Miller esboça não uma teoria sobre uso dos mais variados bens, mas antes sobre as múltiplas possibilidades de objetificação do relacionamento humano.

Muitos outros autores, como Grant McCraken (2003) e Collin Campbell (2001) também tiveram grande importância no desenvolvimento do campo de estudos sobre consumo, no qual se atenta para a agência do consumidor moderno em transformar, apropriar-se e reapropriar-se das mercadorias. Nessa linha de pensamento, Campbell (2005), mais contemporaneamente, desenvolve a noção de craft consumer, em que o ato de consumir é um processo artesanal, 
envolvendo nuanças de elaboração criativa, transformando mercadorias em objetos personalizados.

No que diz respeito ao processo de construção de valor de mercadorias em circulação, o trabalho de Arjun Appadurai (2006) é amplamente reconhecido como um marco na antropologia, ao quebrar o dualismo que distinguia dádivas de mercadorias. A importância da coletânea organizada pelo autor (A vida social das coisas) e, mais precisamente, da sua introdução, foi decisiva para colocar 0 objeto-mercadoria em seu devido lugar de destaque na disciplina - antes voltada apenas para o objeto da dádiva (gift-object) em suas sociedades de dádivas (giftsocieties) $)^{4}$.

Nesse contexto, defende-se que objetos que eram tratados como gifts possam receber o mesmo tratamento analítico que mercadorias, e vice-versa. Esse é o caso de relíquias medievais sagradas que, embora sejam universalmente consideradas como portadoras de força sobrenatural, poder e devoção, também se trata de objetos comprados, vendidos, roubados (GEARY, 2006).

Com o mesmo intuito, mas em outra direção, Appadurai (2006) defende o estudo de mercadorias através de uma lógica bem conhecida aos antropólogos: a do kula. 0 autor sugere que a circulação de mercadorias pode ser analisada segundo o prisma das trocas de dádivas e presentes, isto é, há espírito nas mercadorias. 0 autor discorre sobre a dimensão cultural de tal circulação e, assim, mostra a importância de acompanhar os fluxos de uma mercadoria para que percebamos os diferentes "regimes de valor" que a mesma agrega em movimento e a variação de contexto para contexto: "o desejo e a demanda, o sacrifício recíproco e o poder criam valor econômico em situações específicas." (APPADURAI, 2006, p. 4). Então, é inferido que, assim como as pessoas, os objetos têm vida social e que devemos analisar a sua trajetória "total".

No mesmo livro, Igor Kopytoff (2006) entende que mercadorias devem ser analisadas como processos cognitivos e culturais, e não somente como coisas produzidas, circuladas e trocadas por dinheiro. Assim, seguindo a idéia do conjunto da coletânea sobre a importância de se percorrer "os caminhos" dos

\footnotetext{
${ }^{4}$ Essa discussão sobre gift/commodity está presente na tese de doutorado de Pinheiro-Machado (2009). Basicamente, trabalha-se o papel da dádiva/mercadoria no sistema econômico da China pós-Mao. A autora defende que, para analisar a economia, não é possível distinguir "gift/ commodity societies", pois, no escopo do universo estudado há um entrecruzamento permanente entre mercado e sistemas de trocas tradicionais, bem como de dádivas e mercadorias.
}

TrataR AS COISAS COMO FATOS SOCIAIS...

D. Leitão E R. Machado • 239 
objetos, o autor lança mão da idéia de "biografia das coisas", a qual tem inspirado uma série de pesquisadores nas últimas décadas, estimulando-os a seguir objetos em contextos de circulação cotidiana (FOSTER, 2006).

Miller (2007) reconheceu que, após 20 anos de influência marxista e ênfase na produção, e outros vinte anos de ampla difusão do consumo, está na hora de pensar a mercadoria sob um ponto de vista que congregue ambos os pólos. Appadurai (2006) fala-nos a respeito de uma "mercadoria ecumênica", ou seja, de um processo que une produtores, distribuidores e consumidores. Enquanto possibilidade de análise, isso pode ser entendido como uma espécie de "fetichismo metodológico" ou "fetichismo crítico", que, segundo Foster (2006), significa uma apreciação ou um fascínio pelo estudo da materialidade das coisas em movimento.

Para exemplificar esse processo, pode se citar a pesquisa de PinheiroMachado (2009), na qual se discutem as teorias supracitadas através de um estudo empírico sobre a produção, circulação e consumo de produtos chineses que entram no Brasil, utilizando os estudos contemporâneos sobre global commodity chains. A ênfase é mostrar a relação dialética entre bens e pessoas, sob o ponto de vista da Cultura Material, bem como apontar como bens em movimento unem diferentes tipos de pessoas de países e etnias diferenciadas. Mercadorias produzidas são responsáveis por processos de migração internacional (no âmbito ChinaParaguai-Brasil), bem como pelo deslocamento de milhões de comerciantes (brasileiros que buscam mercadorias para revenda).

Nos anos 2000, a análise de "cadeia global de mercadorias" (GGC do inglês global commodity chain) passou a ser uma nova ferramenta teórica e metodológica para uma análise integrada das diferentes fases da vida de uma mercadoria. Esse estudo começou com um forte vínculo com a teoria de sistemamundo, a qual definia esse processo enquanto uma rede global (centro-periferia) de trabalho e produção que terá como produto uma mercadoria. Segundo Foster (2006), foi Gary Geriffy o autor que estendeu a concepção de GCC para uma rede mais ampla, que abarca de produtores a consumidores.

Bestor (2001, p. 80) entende a estrutura de uma commodity chain como "os links, os estágios, as fases e as mãos através dos quais um produto passa e é transformado, combinado, fabricado e distribuído entre produtores e consumidores". Como mostra Ziegler (2007), o estudo de GCC sofreu inúmeras e significativas alterações, ao perceber o papel de diferentes atores, poderes e 
espacialidades envolvidas no processo mercantil global. Os objetos a serem acompanhados podem ser variados, como flores, peixes, ervilhas e refrigerantes.

Um dos pontos importantes apontados por Bestor (2001), que se diferencia da teoria do sistema-mundo, é que o entendimento GCC também pode ser útil para dar visibilidade ao "ator/comerciante intermediário". Ou seja, não apenas para os grandes produtores hegemônicos, mas como aponta Hughes (2001), para aqueles produtores cuja influência sobre 0 resto da cadeia não é tão direta no sentido de exercer pressão e dominação, mas que possuem importância capital no sistema de distribuição. Na realidade, encontramos aí uma alternativa ao que pode ser classificado como uma polaridade teórica que ora estudou a produção, ora o consumo. Afinal, entre esses dois estágios, existe uma infinidade de atores, espacialidades e políticas de valor pelas quais uma mercadoria vai passar (PINHEIRO-MACHADO, 2009).

Foster (2006) analisa que há duas conseqüências da aplicação das técnicas de cadeia de mercadorias e de seguir bens, uma teórica e a outra política. No que diz respeito à primeira, a vantagens é, como já longamente salientado, perceber como valores são criados em universos relacionais. Já a segunda implicação, a partir dos insights de cultura material sobre a agência dos consumidores, referese à capacidade dos mesmos em recontextualizar as mercadorias em direção a uma visão responsável de um consumidor-cidadão consciente do que consumiu. Miller (2007) escreve algo similar sobre a dimensão política, inferindo que o conhecimento da cadeia ajuda a desfetichizar a mercadoria, pois as relações humanas presentes na mesma são desveladas. Isso serve não para valorizar as condições de trabalho, por exemplo, mas para que o consumidor entenda que 0 preço baixo que ele paga, muitas vezes, é fruto do prejuízo de outrem.

0 que existe hoje no contexto da disciplina é uma pluralidade de estudos que versam sobre o aumento da commodification do mundo. Afinal, os mesmos objetos não são apreciados em todas as partes do mundo e cada qual exerce influência particular sobre os indivíduos: de motocicletas a instrumentos genéticos, de cigarros a computadores. Ao contrário de antigas acepções que viam as mercadorias como uma ameaça à cultura, hoje é notório o fato de que os grupos se apropriam dos objetos de forma singular e que os mesmos, assim como trazem novas experiências e valores, também são enquadrados em cosmologias particulares. Nesse sentido, o trabalho de Sahlins (1997) é revelador quando 
recapitula uma série de etnografias que mostram como "a modernidade" é negociada em sociedades tradicionais.

Como foi abordado até então, os objetos sempre possuíram um lugar central na disciplina antropológica. No entanto, o tema ganhou atenção renovada nas últimas décadas, ao chamar a atenção para a centralidade das "coisas" nas relações sociais. Um dos grandes ganhos que se obteve nessa direção, foi entender que as mercadorias, fruto da industrialização do capitalismo, também podem ser analisadas como detentoras de espírito e de agência, na mesma medida em que são passíveis de sofrerem indigenização de acordo com os sistemas culturais particulares nos quais se inscrevem (APPADURAI, 2006; SAHLINS, 1997). Uma vez levantado um panorama dos estudos de objetos e mercadorias na Antropologia, no próximo item, por fim, argumentaremos que a conciliação entre teorias sobre identidade étnica e a presente discussão de cultura material constitui uma ferramenta analítica frutífera na continuidade dos estudos sobre a relação íntima entre sujeitos e objetos.

\section{ConstruÇÃo de Identidades através dos OBJetos}

Permanecendo no domínio das mercadorias, mas já tratando de casos que concernem à construção de identidades, podemos citar o exemplo daquelas produzidas pela moda brasileira contemporânea. Num esforço recente de divulgação da moda nacional no exterior, nossa moda buscou a inserção de temáticas brasileiras (ou percebidas como tal por seus produtores e divulgadores) nas coleções desenvolvidas, criando o que poderia ser chamado de um "exotismo à brasileira" (LEITÃO, 2007b).

$\mathrm{Na}$ criação de tal exotismo brasileiro, a moda recorre ao uso de elementos culturalmente associados à dimensão da autenticidade e da tradição. Reforçam-se estereótipos sobre um corpo brasileiro erotizado, um caráter nacional influenciado pela natureza exuberante, uma cultura popular "autêntica", entre tantos outros. Ao mesmo tempo, tais estereótipos são aliados a novas representações, como a de que o Brasil pode tornar-se importante produtor de modas "étnicas" e exóticas, assim como de bens voltados para o consumo ético, ecológico e socialmente engajado.

É preciso dizer, no entanto, que a associação entre moda brasileira e produto exótico não acontece apenas quando nossa moda atravessa as fronteiras 
do país. Os discursos acerca da procura das raízes e de voltar para as tradições nacionais discorrem, justamente, sobre o desejo de construir nela algo que possa ser autêntico e típico. Assim, são construídas autenticidades alçadas por parâmetros que certas vezes pendem para o pitoresco e o "turístico".

Procurando lançar um olhar crítico frente a tais apropriações, Leitão (2007a) identificou alguns estereótipos de brasilidade que eram utilizados, tanto pelos produtores de moda quanto pela imprensa especializada, para afirmar a "nacionalidade" da moda brasileira, mostrando as faces do Brasil que estavam sendo expressas através dela. Podemos pensar, entretanto, que mais do que simplesmente expressar uma identidade brasileira passível de ser lida ou decodificada, essa produção de moda estivesse justamente manipulando os estereótipos utilizados para construir as imagens do Brasil.

No caso da moda brasileira também podemos pensar, a exemplo da pesquisa de Pinheiro-Machado (2009), em uma GCC: bens de consumo produzidos no Brasil são comercializados e divulgados na França tendo suas características "brasileiras" enfatizadas, mas retornam ao Brasil e são por aqui promovidos pelo reconhecimento alcançado por eles no exterior. Nesse processo, as mercadorias conectam atores diversos em ambos os países, desde estilistas e empresários até jornalistas e críticos de moda, passando distribuidores, manequins, celebridades midiáticas, vendedores de lojas e consumidores.

As roupas brasileiras, produzidas pela moda e inspiradas em temáticas ditas "nacionais", desfiladas, vendidas e usadas no Brasil ou na França, além de carregar em si significados que remetiam a uma identidade brasileira, contribuíam, em suas trajetórias da passarela às ruas, passando por lojas e revistas, para construir essa mesma identidade As identidades brasileiras promovidas e produzidas não se encontram, portanto, cristalizadas em nenhuma das fases ou locais, pois são construídas através dos objetos em seu próprio processo de circulação.

Em outros processos identitários, como naqueles que envolvem disputas por reconhecimento e políticas de patrimônio, podemos perceber que as coisas (objetos móveis e imóveis) participam ativamente na estruturação dos pertencimentos e no trabalho sobre a memória. É, entretanto, a noção de que os traços (ou objetos) representativos poderão ser variáveis e relativos, escolhidos de acordo com 0 contexto vivido, o que permite que também os objetos cotidianos, não-oficiais, usados no dia-a-dia, possam ser eficazes "fazedores de memória e identidade". 
Bonnot (2002) documenta, por exemplo, o itinerário biográfico de uma garrafa de cidra, analisando a participação desse objeto, aparentemente banal e cotidiano, na construção do patrimônio coletivo. Uma antiga garrafa vazia de cidra, objeto anônimo escolhido para ser representativo da memória de um grupo passou, antes disso, por diversos momentos e significados ao longo de sua trajetória no mundo: em um primeiro momento, ainda cheia, em uso, ocupa o espaço do objeto funcional para, a seguir, tomar o rumo do descarte, transformando-se em lixo. Ela retorna, décadas depois, como patrimônio, e é escolhida como patrimônio por materializar em si a marca da passagem do tempo.

A trajetória dos objetos, como mostra Bonnot (2002), seguindo os passos de Appadurai (2006), são por vezes imprevisíveis, assim como o que fazemos com eles e o que eles fazem conosco. Nesse sentido, para conceber os objetos, anônimos ou "oficiais", como construtores de memórias e identidades, é preciso anteriormente conceder-lhes a possibilidade de agir sobre o mundo social e sobre os sujeitos, e não apenas de representá-los, seja como signo ou como testemunha.

\section{CONSIDERAÇõES FINAIS}

Nosso objetivo neste artigo foi mostrar que a análise dos objetos sob um ponto de vista da cultura material pode constituir um campo fértil no estudo das relações sociais e das identidades sociais. Isso porque, conforme exploramos ao longo do texto, não existe cultura sem objetificação. Concebemo-nos enquanto humanos alicerçados, não apenas no plano simbólico, mas na relação deste com mundo material que nos rodeia. Na antropologia é amplamente aceitável que nós interpretamos, modificamos e criamos materialidades. Os estudos multidisciplinares da Cultura Material, por seu turno, acrescentam que essa relação é sempre dialética: esse mundo também informa, media, cerca. Sujeitos e objetos são indissociáveis: pessoas fazem e usam coisas e coisas fazem pessoas (TILLEY et al., 2006, p. 4).

Assim, poderíamos dizer que, ao passo que uma abordagem do estilo "objeto testemunha" concebe as culturas enquanto "coisas", as abordagens contemporâneas, que compreender os objetos enquanto "construtores", seja de relações sociais, de identidades ou de memórias, concebem as coisas como cultura. Dar lugar aos objetos pode ser um caminho rico, especialmente se atentarmos para as relações que os sujeitos tecem com eles, procurando perceber como atuam, que valores, sentidos e práticas guardam, produzem e reproduzem. Diversos temas 
de pesquisa poderiam contemplar a problemática dos objetos, mas, muito embora percebamos a discussão teórica a respeito das "coisas" como tendo um lugar importante, inclusive para estimular o diálogo entre trabalhos voltados para essa abordagem, certamente serão os casos etnográficos específicos que mostrarão ao pesquisador a importância - ou não - das coisas no contexto pesquisado.

\section{REFERÊNCIAS}

ABREU, Regina. Museus etnográficos e práticas de colecionamento: antropofagia dos sentidos. Revista do Patrimônio Histórico e Artístico Nacional, Rio de Janeiro, n. 31, p. 100-125, 2005.

APPADURAI, Ajurn. Introduction: commodities and the politics of value. In: . The Social Life of Things. Commodities in cultural perspective. Cambridge: Cambridge Univesity Press. 2006, p. 3-63.

BARTHES, Roland. El sistema de la moda y otros escritos. Barcelona: Paidós, 2003.

. Mitologias. Rio de Janeiro: Bertrand Brasil, 2001.

. O óbvio e o obtuso. Rio de Janeiro: Nova Fronteira, 1990.

BAUDRILLARD, Jean. La societé de consommation. Paris: Folio, 1996.

. O sistema dos objetos. São Paulo: Perspectiva, 2002.

BESTOR, Theodore C. Supply-side sushi: commodity, market, and the global city. American anthropology, Washington, v. 103, n. 1, p. 76-95, Mar. 2001.

BONNOT, Thierry. La vie des objets. Paris: Éditions MSH, 2002.

BOURDIEU, Pierre. A dominação masculina. Rio de Janeiro: Bertrand Brasil, 1999.

The berber house, or the World Reversed. Social Science Information, London, v. 9, n. 2, p. 151-170, Apr. 1970.

CAMPBELL, Colin. A Ética Romantica e o Espírito do Consumismo Moderno. Rio de Janeiro: Rocco, 2001.

. The craft consumer. Journal of Consumer Culture, London, v. 5, n. 1, p. 23-42, 2005. 
CLIFFORD, James. Objects and selves: an afterword. In: STOCKING JUNIOR, George W. Objects and others: essays on museums and material culture. Madison: University of Wisconsin Press, 1985.

DOUGLAS, Mary; ISHERWOOD, Baron. 0 mundo dos bens: para uma antropologia do consumo. Rio de Janeiro: Ed. UFRJ, 2004.

FABIAN, Johannes. The ethnic artefact and the ethnographic object. L'Homme, Paris, n. 170, Apr./June. 2004.

FOSTER, Robert J. Tracking Globalization: Commodities and Value in Motion. In: TILLEY, Chris (Ed.) et. al. The Sage Handbook of Material Culture. London: Sage, 2006, p. 285-302.

GEARY, Patrik. Sacred Commodities: the circulation of medieval relics. In: APPADURAI, Arjun (Ed.). The Social Life of Things: Commodities in cultural perspective. Cambridge: Cambridge Univesity Press. 2006, p. 3-63.

GELL, Alfred. Art and Agency. Oxford: Clarendon, 1998.

HUGHES, Alex. Global Commodity Networks, ethnical trade and governmenbility. Transactions of the Institute of British Geographers, London, v. 26, n. 4, p. 390406, Dec. 2001.

KEANE, Webb. Signs are not the garbo of meaning: on the social analysis of material things. In: MILLER, Daniel (Org.). Materiality. London: Duke University Press, 2005.

KOPYTOFF, Igor. The cultural biography of things: commoditization as process. In: APPADURAI, Arjun. The Social Life of Things: Commodities in cultural perspective. Cambridge, Cambridge University Press. 2006, p. 64-94.

LATOUR, Bruno. Une Sociologie sans objets? Remarques sur l'interobjectivité. In: TURGEON, Laurier; DEBRAY, Octave. Objets \& Memóire. Paris: Presses de l'Université de Laval, 2007.

LEITÃO, Débora K. Brasil à moda da casa: imagens da nação na moda brasileira contemporânea. 2007. 373 p. Tese (Doutorado em Antropologia Social) Universidade Federal do Rio Grande do Sul, Porto Alegre. 2007a.

. Nós, os outros: construção do exótico e consumo de moda brasileira na França. Horizontes Antropológicos, Porto Alegre, v. 13, n. 28, p. 203-233. July/ Dec. 2007b. 
MALINOWSKI, Bronislaw. Argonautas do Pacifico ocidental. São Paulo: Abril Cultural, 1978

McCRACKEN, Grant. Cultura \& Consumo. Rio de Janeiro: Mauad, 2003.

MILLER, Daniel. Consumo como cultura material. Horizontes Antropológicos, Porto Alegre, v. 13, n. 28, p. 33-64, July/Dec. 2007.

. Consumption and Commodities. Annual Review of Anthropology, London, v. 24, p. 141-161, Out. 1995.

. Material Culture and Mass Consumption. Oxford: Blackwell, 1987. . Materiality: an introduction. In: MILLER, Daniel (Org.). Materiality. Londres: Duke University Press, 2005.

MORGAN, Lewis. A Sociedade Primitiva. 3. ed. São Paulo: Martins Fontes, 1974. PINHEIRO-MACHADO, Rosana. Made in China: produção e circulação de mercadorias no circuito China - Paraguai - Brasil. 2009. 332 p. Tese (Doutorado em Antropologia Social) - Universidade Federal do Rio Grande do Sul, Porto Alegre, 2009.

SAHLINS, Marshall. 0 Pessimismo Sentimental e a Experiência Etnográfica: Por que a cultura não é um objeto em via de extinção? Mana, v. 3, n. 2, p. 103-150, 1997.

TILLEY, Chris. Introduction. In: TILLEY, Chris et al. (Ed.). Handbook of Material Culture. London: Sage, 2006.

TURGEON, Laurier. La mémoire de la culture mattérielle et la culture matérielle de la mémoire. In: TURGEON, Laurier; DEBRAY, Octave. Objets \& Memóire. Paris: Presses de l'Université de Laval, 2007.

ZIEGLER, Catherine. Favored Flowers. Durham: Duke University Press, 2007. 